\title{
Past the climate optimum: Recruitment is declining at the world's highest juniper shrublines on the Tibetan Plateau
}

\author{
Xiaoming Lu, ${ }^{1,2}$ Eryuan Liang, ${ }^{1,3,9}$ Yafeng Wang ${ }^{4}{ }^{4}$ Flurin Babst, $^{5,6,7}$ Steven W. Leavitt, ${ }^{7}$ and J. Julio Camarero ${ }^{8}$ \\ ${ }^{1}$ Key Laboratory of Alpine Ecology, Institute of Tibetan Plateau Research, Chinese Academy of Sciences, Beijing 100101 China \\ ${ }^{2}$ University of Chinese Academy of Sciences, Beijing 100049 China \\ ${ }^{3}$ CAS Center for Excellence in Tibetan Plateau Earth Sciences, Beijing 100101 China \\ ${ }^{4}$ College of Biology and the Environment, Nanjing Forestry University, Nanjing 210037 China \\ ${ }^{5}$ Dendro Sciences Group, Forest Dynamics Unit, Swiss Federal Research Institute WSL, Zürcherstrasse 111, 8903 Birmensdorf, \\ Switzerland \\ ${ }^{6}$ Department of Ecology, W. Szafer Institute of Botany, Polish Academy of Sciences, ul. Lubicz 46, 31-512 Krakow, Poland \\ ${ }^{7}$ Laboratory of Tree-Ring Research, University of Arizona, 1215 East Lowell Street, Tucson, Arizona 85721 USA \\ ${ }^{8}$ Instituto Pirenaico de Ecología (IPE-CSIC), Avenida Montañana 1005, 50059 Zaragoza, Spain
}

Citation: Lu, X., E. Liang, Y. Wang, F. Babst, S. W. Leavitt, and J. Julio Camarero. 2019. Past the climate optimum: Recruitment is declining at the world's highest juniper shrublines on the Tibetan Plateau. Ecology 100(2):e02557. 10.1002/ecy.2557

\begin{abstract}
Alpine biomes are climate change hotspots, and treeline dynamics in particular have received much attention as visible evidence of climate-induced shifts in species distributions. Comparatively little is known, however, about the effects of climate change on alpine shrubline dynamics. Here, we reconstruct decadally resolved shrub recruitment history (age structure) through the combination of field surveys and dendroecology methods at the world's highest juniper (Juniperus pingii var. wilsonii) shrublines on the south-central Tibetan Plateau. A total of 1,899 shrubs were surveyed at 12 plots located in four regions along an east-to-west declining precipitation gradient. We detected synchronous recruitment with 9 out of 12 plots showing a gradual increase from 1600 to 1900 , a peak at 1900-1940, and a subsequent decrease from the 1930s onward. Shrub recruitment was significantly and positively correlated with reconstructed summer temperature from 1600 to 1940 , whereas it was negatively associated with temperature in recent decades (1930-2000). Recruitment was also positively correlated with precipitation, except in the 1780-1830 period, when a trend toward wetter climate conditions began. Warminginduced drought limitation has likely reduced the recruitment potential of alpine juniper shrubs in recent decades. Ongoing warming without a simultaneous increase in precipitation is expected to further impair recruitment at the world's highest juniper shrublines and alter the dynamics and competitive balance between woody plant species throughout these alpine biomes.
\end{abstract}

Key words: alpine biomes; climate change; dendroecology; drought; dwarf shrub; global warming; Juniperus pingii var. wilsonii; plot; recruitment; shrubline; temperature optimum; Tibetan Plateau.

\section{INTRODUCTION}

The effects of climate warming on terrestrial ecosystems (Stocker et al. 2013) are particularly visible at the edges of species distribution ranges. A prominent example is the transition between forested biomes and the treeless tundra in high latitudes and altitudes. Here, trees and shrubs have expanded beyond their preindustrial limits as a result of rising temperatures (Peñuelas et al. 2007, Harsch et al. 2009, Hallinger et al. 2010, MyersSmith et al. 2011, Elmendorf et al. 2012a, Case and Duncan 2014, Naito and Cairns 2015, Sangüesa-Barreda et al. 2018). Like treeline shifts, a pronounced shrub expansion has profound implications for the

Manuscript received 27 June 2018; revised 22 September 2018; accepted 12 October 2018. Corresponding Editor: Hannah L. Buckley.

${ }^{9}$ Corresponding Author. E-mail: liangey@itpcas.ac.cn structure of the tundra and alpine ecosystems and their feedback to the climate system. For example, shrub expansion may change the surface albedo (Chapin et al. 2005), alter the soil nutrient cycle (Connin et al. 1997, Knapp et al. 2008, Maestre et al. 2009), affect the permafrost layer thickness (Sturm et al. 2001), and reduce vegetation biodiversity (Walker et al. 2006, Joly et al. 2007). In turn, these changes could further amplify warming effects on alpine or Arctic biomes through local positive feedbacks. Evaluating recruitment success is therefore an essential key for understanding shrub range expansion and its effects on the carbon, water, and energy cycles in cold ecosystems.

Shrub recruitment is linked to both biotic and abiotic drivers (Meyer and Pendleton 2005, Moreno et al. 2011, Boulanger-Lapointe et al. 2014). It has been shown that increased summer or winter temperatures strongly favor shrub recruitment in the Arctic tundra (Büntgen et al. 2015, Myers-Smith and Hik 2018). Water availability 
and demand could also codetermine shrub recruitment in drought-prone cold or continental areas (Meyer and Pendleton 2005, Moreno et al. 2011, BoulangerLapointe et al. 2014, Li et al. 2016). In addition, biotic interactions and changes in land management are important for shrub coverage ( $\mathrm{Li}$ et al. 2012, GarcíaCervigón et al. 2013, Olsen and Klanderud 2014). However, despite recent progress in understanding the dynamics and drivers of tundra shrublines, comparatively little is known about recruitment of alpine shrubs under global warming in cold-dry mountainous landscapes, such as the Tibetan Plateau (Wang et al. 2015).

As the largest high-elevation area in the world, the Tibetan Plateau provides a variety of bioclimatic settings to test for the effects of climate change on alpine shrub communities. In this region, Juniperus pingii var. wilsonii (hereafter called juniper shrub) is the most widespread evergreen prostrate shrub and forms the world's highest juniper shrubline at an elevation of 5,280 $\mathrm{m}$ above sea level (Xiaoming Lu, personal observation). Gradual regional warming has been detected during 1600-1900, with an increasing warming rate since 1900 (Thompson et al. 2006, Zhu et al. 2011). These higher temperatures coincide with enhanced climate sensitivity of alpine ecosystems across the Tibetan Plateau (Piao et al. 2014, Liang et al. 2016a), and important changes in the composition and productivity of alpine plant communities can thus be expected in the future. Anticipating the nature and severity of these changes is a research priority that calls for the close monitoring of alpine juniper shrub recruitment. However, such studies have yet to be conducted and climate change impacts on high-elevation shrublines are incompletely understood, despite their relevance to the future functioning of alpine biomes.

In the present study, we combined extensive field measurements with dendroecological analyses in a shrubline plot network situated in the south-central Tibetan Plateau to (1) reconstruct decadal variations of juniper shrub recruitment and (2) identify the climatic drivers that control juniper shrub recruitment across large spatial scales $\left(\sim 300,000 \mathrm{~km}^{2}\right)$. Given that moisture is a limiting factor for juniper shrub growth (Liang et al. 2012) and that a lack of tree recruitment has been observed in semiarid areas of the northeastern Tibetan Plateau under climate warming (Liang et al. 2016a), we hypothesize that warming-induced drought stress could also negatively affect the recruitment of alpine juniper shrubs, and such an effect is stronger at the semiarid edge of the sampled gradient on the southcentral Tibetan Plateau. To test these hypotheses, we reconstructed shrubline age structure and recruitment along an east-west gradient from wetter to drier conditions.

\section{Materials And Methods}

\section{Study sites and climate}

This study was conducted at four main juniper shrubline (defined as the upper limit of juniper shrub) sites located on the south-central Tibetan Plateau (Fig. 1, $\left.28.5^{\circ}-32.0^{\circ} \mathrm{N}, 84.5^{\circ}-93.0^{\circ} \mathrm{E}\right)$. The four selected regions (from east to west) are Songduo (SD), Damxung (DX), Namling (NM), and Saga (SG; Fig. 1; Appendix S1: Table S1). Sites range in elevation from 4,933 to $5,220 \mathrm{~m}$. These shrubline sites are largely undisturbed by human activities (e.g., fire, grazing, and logging). There is also no obvious evidence of insect attack, fungal infection, or wounding. The study area is located in a transition zone that is seasonally affected by the Indian summer monsoon and westerly winds. It is characterized by alpine semi-humid climate conditions in the east and alpine semiarid climate conditions in the west. In summer, the study region is mainly influenced by the Indian summer monsoon and associated precipitation pulses (Tian et al. 2001). In winter, climate is mainly driven by the westerly wind system. There are eight meteorological stations in the study area (locations shown in Fig. 1b). According to station data, the annual mean temperature (AMT) and annual mean total precipitation (AP) range from $-1.1^{\circ} \mathrm{C}$ (Naqu, $1955-2014$ record) to $8.8^{\circ} \mathrm{C}$ (Zedang, 1960-2014 record) and from $274 \mathrm{~mm}$ (Tingri, 1959-2014 record) to $476 \mathrm{~mm}$ (Damxung, 1963-2013 record), respectively (Appendix S1: Fig. S1). We observed a significant warming trend $\left(>0.2^{\circ} \mathrm{C}\right.$ per decade) across all meteorological stations during the 19632013 period. However, AP significantly increased only at three meteorological stations (Baingoin, Naqu, and Xainza) over the same period (Fig. 2a).

As the available instrumental climate data are limited to approximately the past five decades, we used existing climate reconstructions to assess the variability of temperature and precipitation on the Tibetan Plateau during the period of 1600-2000. The $z$ scores of a tree-ringbased summer temperature reconstruction on the southern Tibetan Plateau were used as a proxy of summer air temperature variability (Zhu et al. 2011). This temperature proxy indicates a warming trend since 1900 (Fig. 2b). Last, glacier snow accumulation in Dasuopu was used as a precipitation proxy (Thompson et al. 2000) and showed a gradual increase from 1800 to 1880 and a slight decrease thereafter (Fig. 2c).

\section{Field sampling and dendroecological methods}

Three rectangular plots $(30 \times 150 \mathrm{~m})$ were established in each region (SD, DX, NM, and SG) from July to September in 2014 and 2016. We used Global Positioning System (GPS) to record the geographic location of each plot at $\pm 5 \mathrm{~m}$ accuracy. The long side of each plot was oriented parallel to the slope direction (Camarero and Gutiérrez 2004, Wang et al. 2016b), with the upper side set above the current elevation of the shrubline. The basal stem diameter of each shrub within a plot was then measured using diameter tapes (Wang et al. 2015). From each shrub, we measured the thickest basal stem and assumed that it was the oldest stem. In total, we surveyed 1,899 juniper shrubs in the 12 shrubline 


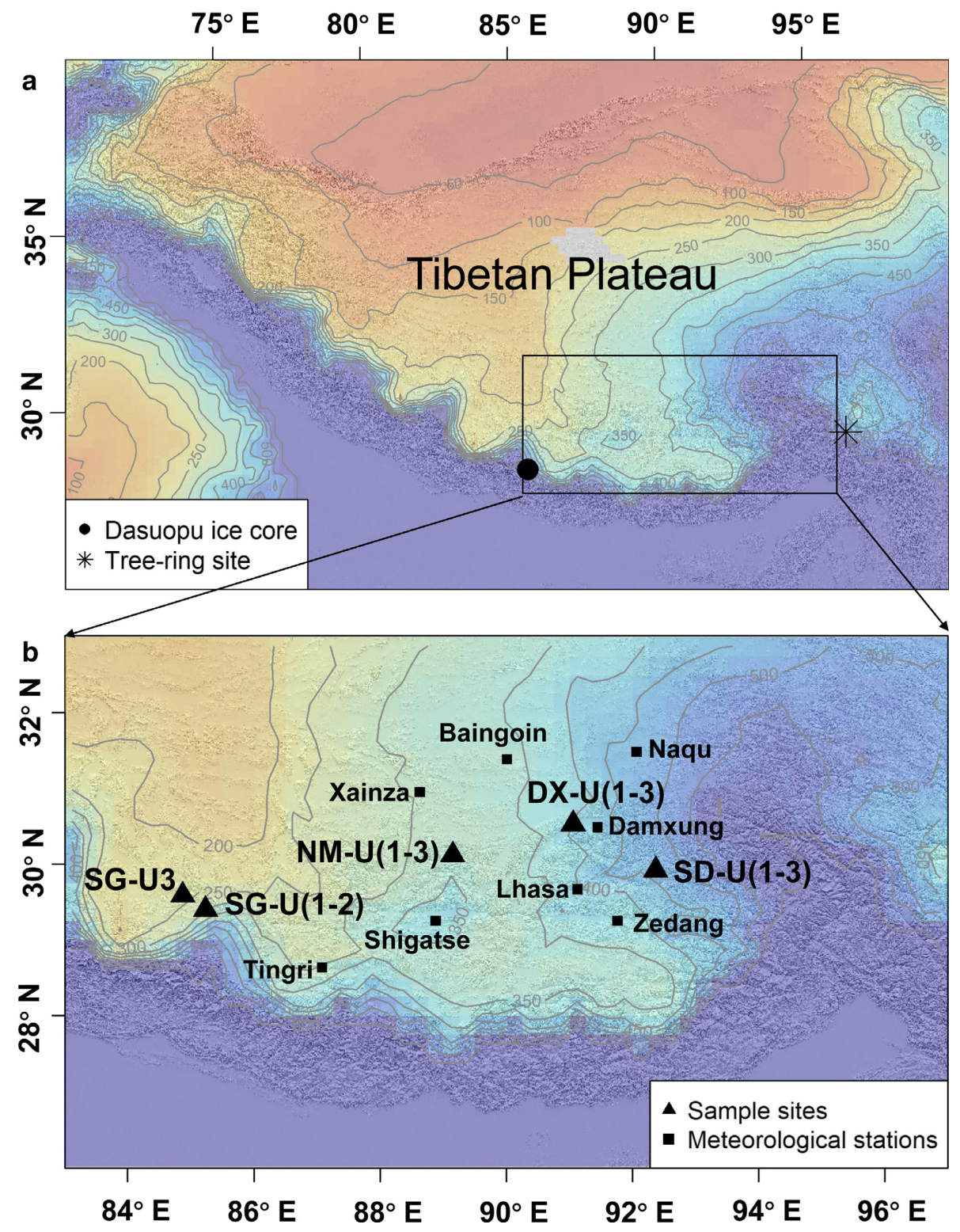

FIG. 1. Location of the study area, annual precipitation isoline ( $\mathrm{mm}$ ), and climate proxies (ice core and tree-ring sites) on (a) the Tibetan Plateau and (b) the shrubline sites (black triangles) on the south-central Tibetan Plateau. The meteorological stations used in this study are indicated by black squares.

plots located across the four studied regions. During our field surveys, we found very few seedlings and saplings, and no dead juniper shrubs were observed in each plot. In the period 2001-2010, among all sites only two individuals established in DX-U1 and one individual established in NM-U3. No recruitment from 2011 to 2014/ 2016 was detected within the sampled plots.

Juniper shrubs form well-defined annual growth rings that have proven to be reliable for dendrochronological dating (Liang et al. 2012). Thus, we used standard dendroecological techniques to estimate the ages of all the measured shrubs, as has often been done in treeline and shrubline studies (Camarero and Gutiérrez 2004, Liang et al. 2011, García-Cervigón et al. 2017, Sigdel et al. 2018). Additionally, a total of 277 juniper shrubs with different basal stem diameters located just outside the shrubline plots were selected to represent different age classes. Their approximately round cross-sections were then collected to establish age-diameter relationships for the four study regions (DX, $n=54$ shrubs; NM, $n=67$ shrubs; SG, $n=105$ shrubs; $\mathrm{SD}, n=51$ shrubs). These cross-sections were sampled at the thickest stem base from each shrub, air dried, and sanded using progressively finer sandpapers until the ring boundaries were clearly visible. After polishing, we estimated the shrub age as the maximum number of growth rings counted 


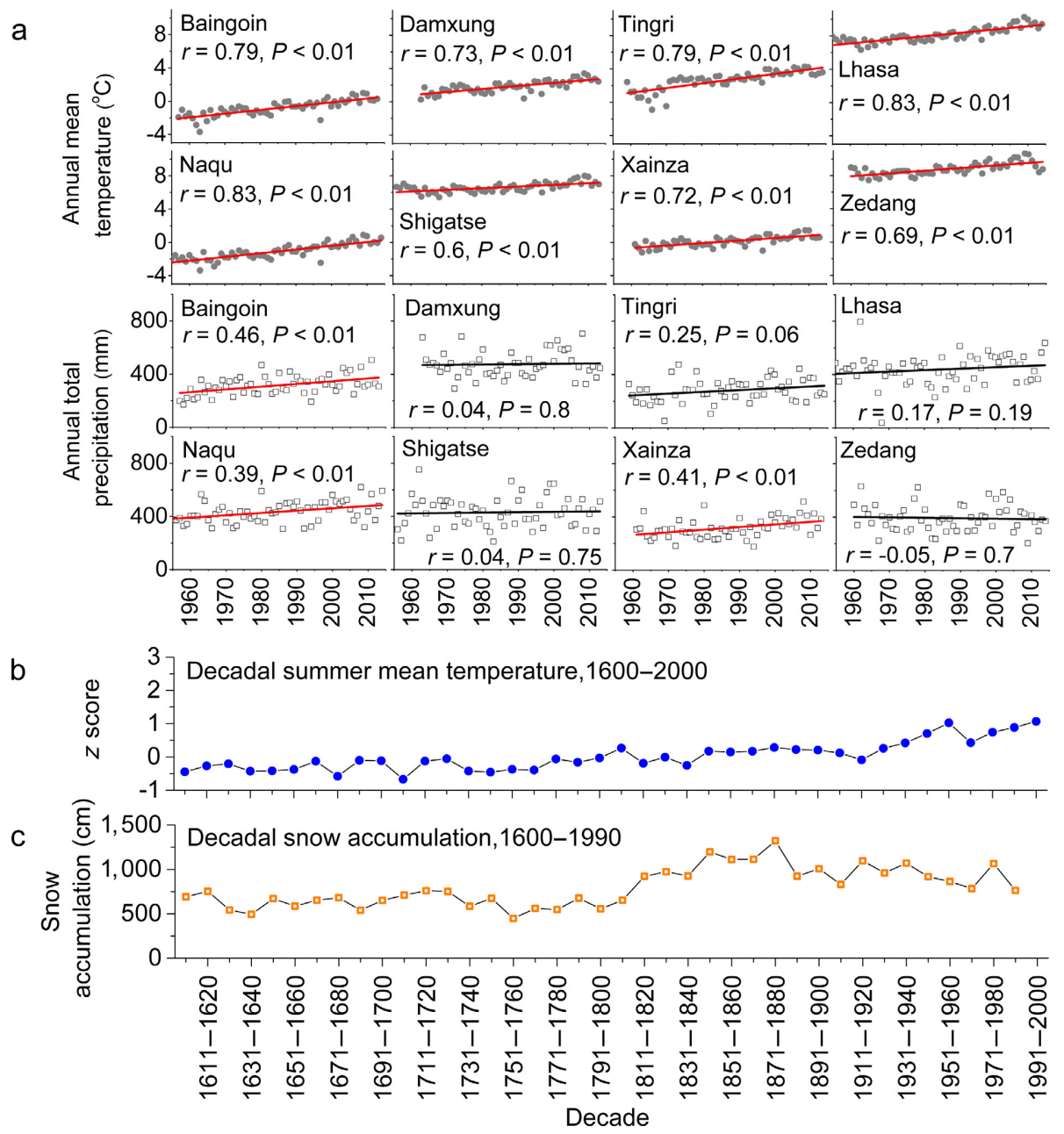

FIG. 2. (a) Trends of annual mean temperature and annual total precipitation of the eight meteorological stations considered in study area. The red lines indicate significantly $(P<0.05)$ increasing trends. The black lines indicate that the increasing trend is not significant $(P>0.05)$. (b) The lower plots show the variations of decadal summer mean temperature reconstructed from tree rings and (c) snow accumulation reconstructed from the Dasuopu ice core in the study area.

along two radii of each disc, and we measured the diameter of these cross-sections. Thus, we established an age-diameter relationship separately for each of the four regions (Appendix S1: Fig. S2). The mean errors between ages estimated with this relationship and actual ages from their basal stem diameters were $<11$ yr (DX, $9 \pm 6 \mathrm{yr}$; NM, $11 \pm 7 \mathrm{yr}$; SG, $11 \pm 6 \mathrm{yr}$; SD, $8 \pm 5 \mathrm{yr}$ ). We subsequently estimated the age of all 1,899 individuals at decadal resolution. The oldest individual attains age up to $771 \mathrm{yr}$ at SG-U3. Given that very few shrubs established before 1600 , we reconstructed the recruitment history of juniper shrubs from 1600 to 2010.

The age structure of juniper shrubs is fundamental to understanding population dynamics in shrublines. Given the present lack of seedlings and saplings in most plots, the recruitment refers to the number of juniper shrubs that established in older time intervals and survived to a large size (basal stem diameter $>0.5 \mathrm{~cm}$ ). The population age structure in the plots was considered to be a result of the balance between recruitment and mortality (Wang et al. 2016a). If climate change enhances shrub establishment more than mortality, population density is expected to increase. As recruitment has higher climate sensitive than mortality, changes in shrub recruitment are expected to be more rapid than changes in mortality at the shrubline (Lloyd 1997). Consequently, we assumed that mortality was low and constant across the 12 plots. Most of the analyses presented herein, and indeed similar analyses from other treeline studies, are based on similar assumptions (Camarero and Gutiérrez 2004, Auger and Payette 2010, Liang et al. 2016b, Wang et al. 2016a).

\section{Statistical analyses}

Differences in the decadal recruitment series (defined as variation of the number of juniper shrubs established 
in decadal time intervals) among the 12 plots were assessed using the Kruskal-Wallis test. The mean value of the 12 recruitment series was used to quantify the recruitment pattern of the whole study area. We calculated Spearman correlations between the 12 recruitment series. The relationships between decadal recruitment series and reconstructed climate were also determined using Spearman correlations. The tree-ring-based summer temperature reconstruction (Zhu et al. 2011) and the reconstructed precipitation derived from glacier accumulation rates (Thompson et al. 2000) overlap with the shrub recruitment chronologies in the periods 1600 2000 and 1600-1990, respectively. Thus, the last decade of recruitment (2001-2010) was not analyzed. In addition, a moving-window of Spearman correlations between the mean value of the 12 shrub recruitment series and climate was used to detect periods with changing climate-recruitment relationships. We selected a moving-window of $70 \mathrm{yr}$ for this analysis.

\section{RESULTS}

We reconstructed the decadal shrub population age structure in the 12 plots from 1600 to 2010 (Fig. 3). Kruskal-Wallis tests showed that the recruitment is consistent among the 12 plots $\left(\chi^{2}=9.48, \quad \mathrm{df}=11\right.$, $P=0.58)$. As shown by the Spearman correlations, recruitment patterns were consistent between the three plots at each site (Appendix S1: Table S2). Among the four study sites, the recruitment in SD was similar to that observed at the DX, NM, and SG sites (except for SG-U3). The recruitment in DX-U1 and DX-U2 has

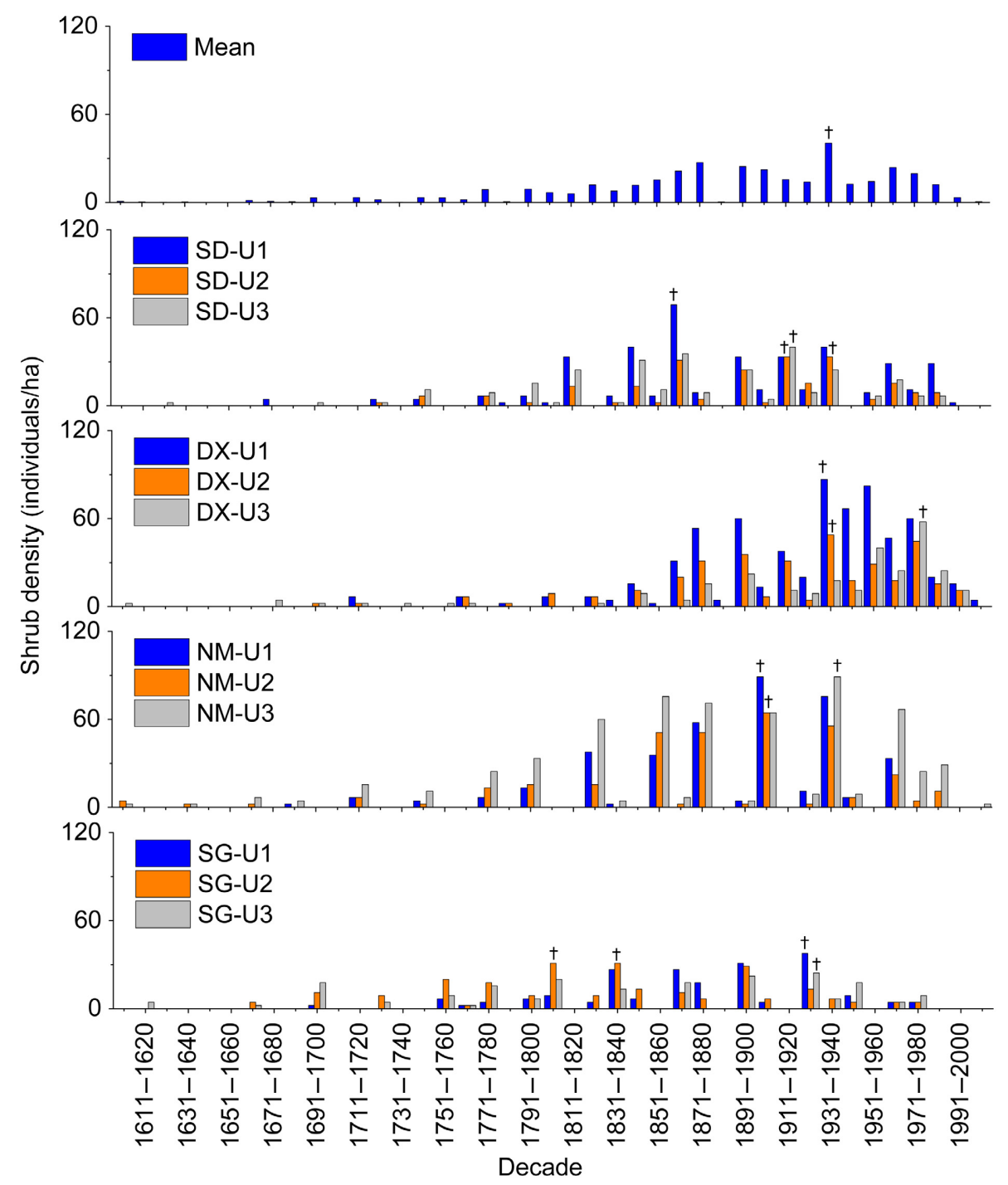

FIG. 3. Decadal shrub recruitment series reconstructed in 12 shrubline plots and their mean recruitment series from 1600 to 2010 (individuals/ha). The recruitment peak in each plot is indicated by the $\uparrow$ symbol. Note that the SD-U2 and SG-U2 plots have two recruitment peaks. 
significant positive correlations with NM-U2 and SGU1, whereas correlations were lower between the DXU3, NM, and SG sites. The recruitment in DX-U1 was similar to that of NM-U1 and NM-U3. Similarities in recruitment between plots at the NM and SG sites were also found (e.g., NM-U1, SG-U1, and SG-U2). By contrast, the recruitment pattern in SG-U3 differed from that of the other three sites.

The recruitment series in nine plots (DX-U1, DX-U2, NM-U1, NM-U2, NM-U3, SG-U1, SG-U3, SD-U2, and SD-U3 plots; see Fig. 3) had the maximum recruitment rate during the period from 1900 to 1940 . In spite of the continued rise in temperature thereafter (Fig. 2), the recruitment (excepting DX-U3) decreased after the 1930s (Fig. 3). The decadal summer mean temperature was positively related to shrub recruitment from 1600 to 1940, but negative associations were observed from 1930 to 2000 (except in DX-U3; Fig. 4). The reconstructed precipitation series was positively associated with shrub recruitment for the 1600-1940 and 1930-1990 periods (except in the SG-U3 and DX-U3 plots). The correlations between the mean recruitment series and climate factors were, in general, similar to those found at individual sites. The moving-window Spearman correlation analysis indicates that the positive effect of summer temperature changed to negative after 1940 (Fig. 4b). In
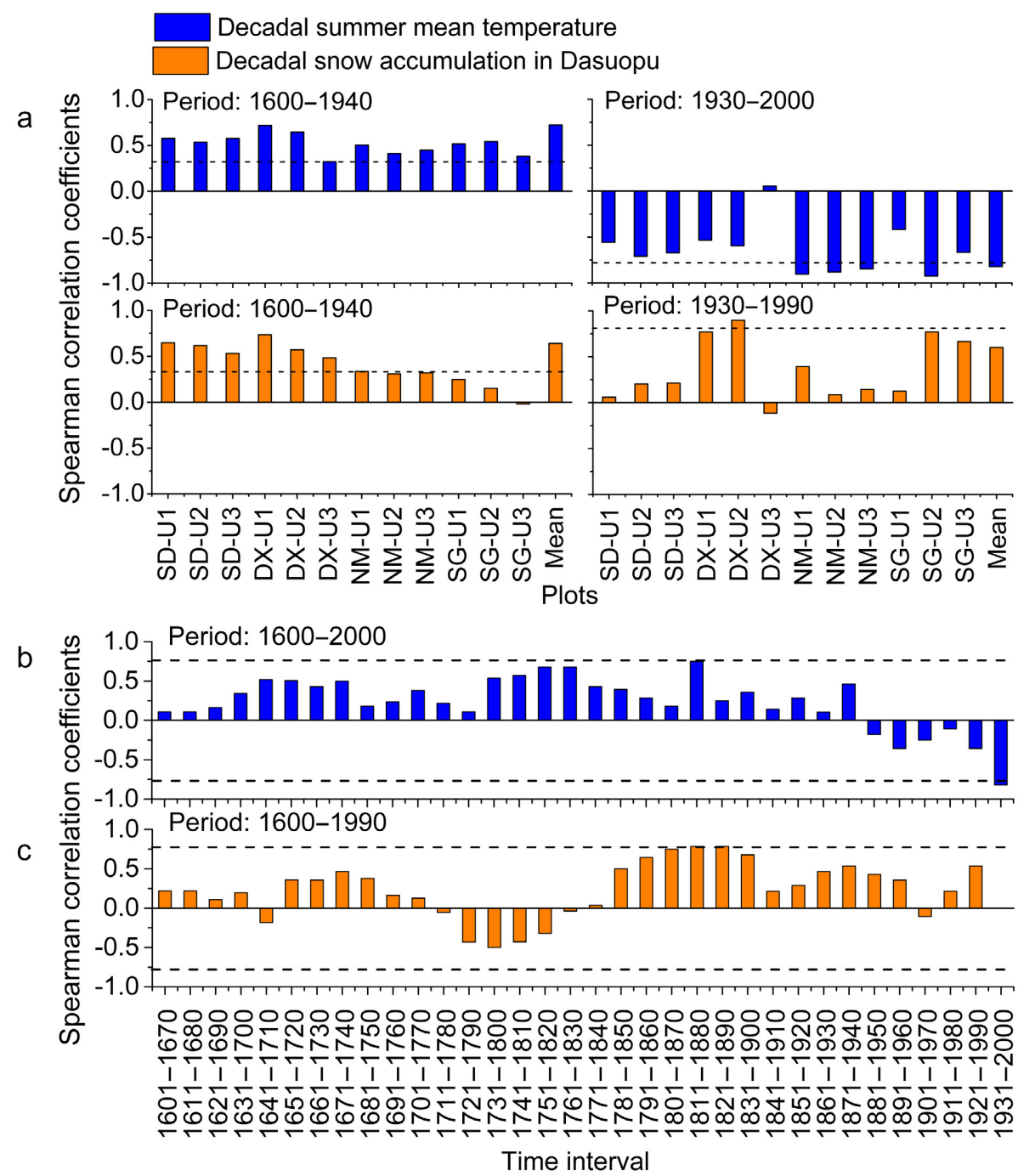

FIG. 4. (a) Results of Spearman correlation analyses relating the decadal shrub recruitment series of 12 shrubline plots to reconstructed climate variables for the Tibetan Plateau. Spearman correlation analyses between the mean series of 12 recruitment sites and climatic variables are shown in the last column of each graph in panel a. Spearman moving-window (window size: $70 \mathrm{yr}$ ) correlation results between the mean recruitment series of all 12 shrubline plots and climate variables are also shown panels $\mathrm{b}$ and $\mathrm{c}$. Climate variables include decadal summer mean temperature (based on tree-ring width data) and decadal precipitation (based on glacier snow accumulation in Dasuopu). The analysis period is indicated in the top left corner of each graph. The dashed horizontal lines indicate the significance level $(P<0.05)$. 
addition, negative moving-window correlations between precipitation and the mean recruitment series were observed in the period of 1780-1830 (Fig. 4c), during which a gradual increase in reconstructed precipitation occurred (Fig. 2c).

\section{Discussion}

Juniper shrublines on the south-central Tibetan Plateau provide an excellent setting to reconstruct the age structure of treeless alpine communities over the past four centuries. The age structures of tall trees are often related to climatic change and disturbance regimes (Villalba and Veblen 1997). Taking into account that very few disturbances affected the four shrubline sites, climatic change is likely to be the main driver of variations in their age structures. Accordingly, most study plots showed a common recruitment pattern (Appendix S1: Table S2). The dominant role of macroclimate is further confirmed by a significant correlation between the mean recruitment series of the shrubline network and temperature from 1600 to 2000. Being similar to the recruitment at the upper treelines in the Rocky Mountains (Elliott 2011), juniper shrub recruitment is also affected by site-specific factors (e.g., microtopography, aspect, plant interactions), and not all local recruitment patterns were similar between the 12 sampled plots. For example, the SG-U3 site was the highest shrubline $(5,220 \mathrm{~m}$ above sea level), and its recruitment showed weak but positive correlations with that in SD, DX, and NM sites.

Temperature played an important role in driving the recruitment of junipers at the high-elevation shrubline (Fig. 4). However, the influence of warming on recruitment shifted in the 1930s, when we detected a transition in the climate-recruitment relationships (Fig. 4). Prior to the 1930s, positive effects of temperature on shrub recruitment indicated that milder climate conditions benefit shrub regeneration. Such a pattern has also been found in the Arctic tundra (Elmendorf et al. 2012a, Myers-Smith and Hik 2018). Generally, the seed germination period is critical in the recruitment process of alpine woody plants (Körner 2003). Manipulative studies on shrub recruitment have suggested that summer warming substantially decreases the seed germination time and increases seed germination rates (Graae et al. 2008). Summer warming is usually associated with a longer growing season, which may further increase the chance of seedling survival (Milbau et al. 2009). At the treeline, increased summer and winter temperatures are assumed to promote seed viability and recruitment by reducing the possibility of frost damage and desiccation injury (Kullman 2014).

In contrast to the $1600-1940$ period, our results indicate negative effects of warming on shrub regeneration after the 1930s (Fig. 4). This suggests that the climate optimum for recruitment was reached around the 1930s and that warming-induced drought stress subsequently limited shrub regeneration. Similarly, a recent global meta-analysis has shown that shrub abundance is not sustained as warming progresses in tundra areas (Elmendorf et al. 2012b). In addition, a lack of shrub recruitment was also observed in response to abnormal warming during recent years in polar dry biomes (Boulanger-Lapointe et al. 2014, Büntgen et al. 2015). In several drought-prone treeline sites worldwide, low tree recruitment has also been observed in recent decades (Cuevas 2002, Camarero and Gutiérrez 2004, Dulamsuren et al. 2010, Khansaritoreh et al. 2017, Xu et al. 2017). Drought stress may be even more intense at shrublines, where rocky and shallow sandy soils amplify evaporation and soil moisture loss under warming climate.

Moisture availability is considered to significantly affect recruitment in arid areas (Kitzberger et al. 2000, Waal et al. 2009). For example, rapid glacier melting supplied sufficient moisture for willow shrub (Salix arctica Pall.) colonization in glacier forelands in the High Arctic (Boulanger-Lapointe et al. 2014). The predominance of birch (Betula nana L.) shrubs in dry northeastern Siberia could also be related to high summer precipitation ( $\mathrm{Li}$ et al. 2016). By contrast, our study area is characterized by cold and dry alpine conditions with high radiation and evaporation levels (Liang et al. 2012). It is thus feasible that moisture availability has become a primary limiting factor of recruitment rate, in particular under a high solar radiation (Bader et al. 2007). It is clear that most of the sampled juniper shrubs established in periods with suitable temperatures and abundant water supply from 1600 to 1940 . However, the instrumental climate data show that precipitation has not significantly increased across the study area during the past five decades (Fig. 2a). In addition, the reconstructed precipitation derived from glacier accumulation rates and tree-ring $\delta^{18} \mathrm{O}$-derived hydroclimate reconstructions from the southern Tibetan Plateau have shown a drying trend since the 1930s (Thompson et al. 2000, Grießinger et al. 2011, Liu et al. 2014). Together with the continuous warming effect, we conclude that the decline in juniper shrub recruitment has resulted from increasing drought stress in our study area. Future studies should test whether such changing relationships between shrub regeneration and rising temperatures depend on threshold-type responses to climate (Elliott 2012), or if they are also affected by local-scale biotic interactions (García-Cervigón et al. 2013, Elliott and Cowell 2015, Liang et al. 2016b, Lett and Dorrepaal 2018). If shrub recruitment at shrubline decreases in the future, such biotic interactions would greatly affect the biodiversity and composition of alpine biomes and the capacity of these communities to regulate carbon and water cycles at high elevations. Interestingly, the period during which precipitation had a negative effect on shrub recruitment (1780-1830) coincides with the Little Ice Age (LIA) that preceded a wet climate phase. The cold conditions during the LIA likely delayed snow-melt and the onset of growth season, leading to reduced shrub recruitment. 
Our results do not support the initial hypothesis that warming-induced drought stress is stronger at the semiarid edge of the sampled gradient. For example, recruitment at the SG-U1 and SG-U3 plots showed lower temperature sensitivity than at the SD and NM sites (excepting SD-U1) during the recent decades. It is likely that elevation-related precipitation changes play an important role in regulating the climatic sensitivity of juniper shrub recruitment. The meteorological records along the altitudinal range from $\sim 4,400$ to $5,300 \mathrm{~m}$ at the DX site show increasing precipitation with increasing elevation up to $5,100 \mathrm{~m}$, and then slightly decreasing precipitation at higher elevations ( $\mathrm{Li}$ et al. 2013). The elevation of the shrubline gradually increases from east (SD) to west (SG) in our study area (Appendix S1: Table S1). Enhanced precipitation and reduced temperature with increasing elevation may buffer the drought stress at the western sites.

The decline in recruitment of woody plants and the negative effect of climate warming is a new challenge for alpine ecosystems. Recently, warming-induced drought stress has already resulted in growth decline and increased tree mortality events in semiarid mountain forests (Liu et al. 2013, Allen et al. 2015, Xu et al. 2017, Andrus et al. 2018). Furthermore, several studies showed that interactions between temperature and precipitation leading to dry conditions limit seedling establishment and tree species distribution shifts in the Rocky Mountains (Hessl and Baker 1997, Lloyd and Graumlich 1997, Elliott 2012, Moyes et al. 2015, Kueppers et al. 2017). High-elevation forests on the dry northeastern Tibetan Plateau are increasingly at risk of growth decline and mortality (Liang et al. 2016a, Fang et al. 2018, Ren et al. 2018). In addition, drought has also increased the frequency of missing rings in alpine birch forests in the central Himalayas (Liang et al. 2014). There has also been an increasing negative impact of atmospheric vapor pressure deficit on alpine grassland productivity (Shen et al. 2015, Ding et al. 2018). This combined evidence, together with the findings presented herein, suggests that warming climate may trigger unprecedented changes in alpine and subalpine ecosystems, which are associated with amplified drought stress.

To conclude, our findings provide new evidence of changing sensitivity of alpine juniper shrub recruitment to global warming at the world's highest shrublines situated on the Tibetan Plateau. Alpine shrub recruitment is a key ecological indicator that provides early warning signs of climate change-induced changes in alpine ecosystems. The increasing shrub recruitment prior to the 1930s was followed by a decrease toward present, suggesting that a temperature optimum for shrub recruitment was reached and passed. Hence, further warming is expected to reduce the resilience and increase the vulnerability of alpine shrublands. Given the forecasted acceleration of climate warming, a decreasing trend in shrub recruitment is expected in response to increasing warming-induced drought stress across these alpine areas.

\section{ACKNOWLedgments}

This study is supported by the National Natural Science Foundation of China (41471158), the Strategic Priority Research Program of Chinese Academy of Sciences (XDA20050101), and the National Science Fund for Distinguished Young Scholars (41525001). X. Lu acknowledges the financial support from China Postdoctoral Science Foundation (2017M620924), and E. Liang acknowledges the Youth Innovation Promotion Association, CAS. F. Babst acknowledges the funding from the EU-H2020 program (grant 640176, "Detecting changes in essential ecosystem and biodiversity propertiestowards a Biosphere Atmosphere Change Index: BACI").

\section{Literature Cited}

Allen, C. D., D. D. Breshears, and N. G. McDowell. 2015. On underestimation of global vulnerability to tree mortality and forest die-off from hotter drought in the Anthropocene. Ecosphere 6:129.

Andrus, R. A., B. J. Harvey, K. C. Rodman, S. J. Hart, and T. T. Veblen. 2018. Moisture availability limits subalpine tree establishment. Ecology 99:567-575.

Auger, S., and S. Payette. 2010. Four millennia of woodland structure and dynamics at the Arctic treeline of eastern Canada. Ecology 91:1367-1379.

Bader, M. Y., I. van Geloof, and M. Rietkerk. 2007. High solar radiation hinders tree regeneration above the alpine treeline in northern Ecuador. Plant Ecology 191:33-45.

Boulanger-Lapointe, N., E. Lévesque, S. Boudreau, G. H. R. Henry, and N. M. Schmidt. 2014. Population structure and dynamics of Arctic willow (Salix arctica) in the High Arctic. Journal of Biogeography 41:1967-1978.

Büntgen, U., L. Hellmann, W. Tegel, S. Normand, I. MyersSmith, A. V. Kirdyanov, D. Nievergelt, and F. H. Schweingruber. 2015. Temperature-induced recruitment pulses of Arctic dwarf shrub communities. Journal of Ecology 103:489-501.

Camarero, J. J., and E. Gutiérrez. 2004. Pace and pattern of recent treeline dynamics: Response of ecotones to climatic variability in the Spanish Pyrenees. Climatic Change 63:181200.

Case, B. S., and R. P. Duncan. 2014. A novel framework for disentangling the scale-dependent influences of abiotic factors on alpine treeline position. Ecography 37:838-851.

Chapin, F. S., et al. 2005. Role of land-surface changes in Arctic summer warming. Science 310:657-660.

Connin, S. L., R. A. Virginia, and C. P. Chamberlain. 1997. Carbon isotopes reveal soil organic matter dynamics following arid land shrub expansion. Oecologia 110:374-386.

Cuevas, J. G. 2002. Episodic regeneration at the Nothofagus pumilio alpine timberline in Tierra del Fuego, Chile. Journal of Ecology 90:52-60.

Ding, J., T. Yang, Y. Zhao, D. Liu, X. Wang, Y. Yao, S. Peng, T. Wang, and S. Piao. 2018. Increasingly important role of atmospheric aridity on Tibetan alpine grasslands. Geophysical Research Letters 45:2852-2859.

Dulamsuren, C., M. Hauck, M. Khishigjargal, H. H. Leuschner, and C. Leuschner. 2010. Diverging climate trends in Mongolian taiga forests influence growth and regeneration of Larix sibirica. Oecologia 163:1091-1102.

Elliott, G. P. 2011. Influences of 20th-century warming at the upper tree line contingent on local-scale interactions: Evidence from a latitudinal gradient in the Rocky Mountains, USA. Global Ecology and Biogeography 20:46-57.

Elliott, G. P. 2012. Extrinsic regime shifts drive abrupt changes in regeneration dynamics at upper treeline in the Rocky Mountains, USA. Ecology 93:1614-1625. 
Elliott, G. P., and C. M. Cowell. 2015. Slope aspect mediates fine-scale tree establishment patterns at upper treeline during wet and dry periods of the 20th Century. Arctic, Antarctic, and Alpine Research 47:681-692.

Elmendorf, S. C., et al. 2012a. Plot-scale evidence of tundra vegetation change and links to recent summer warming. Nature Climate Change 2:453-457.

Elmendorf, S. C., et al. 2012b. Global assessment of experimental climate warming on tundra vegetation: heterogeneity over space and time. Ecology Letters 15:164-175.

Fang, O., R. I. Alfaro, and Q. B. Zhang. 2018. Tree rings reveal a major episode of forest mortality in the late 18th century on the Tibetan Plateau. Global and Planetary Change 163:44-50.

García-Cervigón, A. I., A. Gazol, V. Sanz, J. J. Camarero, and J. M. Olano. 2013. Intraspecific competition replaces interspecific facilitation as abiotic stress decreases: The shifting nature of plant-plant interactions. Perspectives in Plant Ecology Evolution and Systematics 15:226-236.

García-Cervigón, A. I., E. Velázquez, T. Wiegand, A. Escudero, and J. M. Olano. 2017. Colonization in Mediterranean oldfields: the role of dispersal and plant-plant interactions. Journal of Vegetation Science 28:627-638.

Graae, B. J., I. G. Alsos, and R. Ejrnaes. 2008. The impact of temperature regimes on development, dormancy breaking and germination of dwarf shrub seeds from arctic, alpine and boreal sites. Plant Ecology 198:275-284.

Grießinger, J., A. Bräuning, G. Helle, A. Thomas, and G. Schleser. 2011. Late Holocene Asian summer monsoon variability reflected by $\delta^{18} \mathrm{O}$ in tree-rings from Tibetan junipers. Geophysical Research Letters 38:L03701.

Hallinger, M., M. Manthey, and M. Wilmking. 2010. Establishing a missing link: warm summers and winter snow cover promote shrub expansion into alpine tundra in Scandinavia. New Phytologist 186:890-899.

Harsch, M. A., P. E. Hulme, M. S. McGlone, and R. P. Duncan. 2009. Are treelines advancing? A global meta-analysis of treeline response to climate warming. Ecology Letters 12:10401049

Hessl, A. E., and W. L. Baker. 1997. Spruce and fir regeneration and climate in the forest-tundra ecotone of Rocky Mountain National Park, Colorado, USA. Arctic, Antarctic, and Alpine Research 29:173-183.

Joly, K., R. R. Jandt, C. R. Meyers, and M. J. Cole. 2007. Changes in vegetative cover on Western Arctic Herd winter range from 1981 to 2005: potential effects of grazing and climate change. Rangifer 17:199-207.

Khansaritoreh, E., C. Dulamsuren, M. Klinge, T. Ariunbaatar, B. Bat-Enerel, G. Batsaikhan, K. Ganbaatar, D. Saindovdon, Y. Yeruult, and J. Tsogtbaatar. 2017. Higher climate warming sensitivity of Siberian larch in small than large forest islands in the fragmented Mongolian forest steppe. Global Change Biology 23:3675-3689.

Kitzberger, T., D. F. Steinaker, and T. T. Veblen. 2000. Effects of climatic variability on facilitation of tree establishment in northern Patagonia. Ecology 81:1914-1924.

Knapp, A. K., et al. 2008. Consequences of more extreme precipitation regimes for terrestrial ecosystems. BioScience 58:811-821.

Körner, C. 2003. Alpine plant life: functional plant ecology of high mountain ecosystems. Springer, Berlin, Germany.

Kueppers, L. M., E. Conlisk, C. Castanha, A. B. Moyes, M. J. Germino, P. de Valpine, M. S. Torn, and J. B. Mitton. 2017. Warming and provenance limit tree recruitment across and beyond the elevation range of subalpine forest. Global Change Biology 23:2383-2395.

Kullman, L. 2014. Treeline (Pinus sylvestris) landscape evolution in the Swedish Scandes-a 40-year demographic effort viewed in a broader temporal context. Norwegian Journal of Geography 68:155-167.

Lett, S., and E. Dorrepaal. 2018. Global drivers of tree seedling establishment at alpine treelines in a changing climate. Functional Ecology 32:1666-1680.

Li, M. H., Z. Du, H. L. Pan, C. F. Yan, W. F. Xiao, and J. P. Lei. 2012. Effects of neighboring woody plants on target trees with emphasis on effects of understorey shrubs on overstorey physiology in forest communities: a mini-review. Community Ecology 13:117-128.

Li, R., T. Luo, Y. Tang, M. Du, and X. Zhang. 2013. The altitudinal distribution center of a widespread cushion species is related to an optimum combination of temperature and precipitation in the central Tibetan Plateau. Journal of Arid Environments 88:70-77.

Li, B., M. M. P. D. Heijmans, F. Berendse, D. Blok, T. Maximov, and U. Sass-Klaassen. 2016. The role of summer precipitation and summer temperature in establishment and growth of dwarf shrub Betula nana in northeast Siberian tundra. Polar Biology 39:1245-1255.

Liang, E., Y. Wang, D. Eckstein, and T. Luo. 2011. Little change in the fir tree-line position on the southeastern Tibetan Plateau after 200 years of warming. New Phytologist 190:760-769.

Liang, E., X. Lu, P. Ren, X. Li, L. Zhu, and D. Eckstein. 2012. Annual increments of juniper dwarf shrubs above the tree line on the central Tibetan Plateau: a useful climatic proxy. Annals of Botany 109:721-728.

Liang, E., B. Dawadi, N. Pederson, and D. Eckstein. 2014. Is the growth of birch at the upper timberline in the Himalayas limited by moisture or by temperature? Ecology 95:24532465.

Liang, E., C. Leuschner, C. Dulamsuren, B. Wagner, and M. Hauck. 2016a. Global warming-related tree growth decline and mortality on the north-eastern Tibetan plateau. Climatic Change 134:163-176.

Liang, E., Y. Wang, S. Piao, X. Lu, J. J. Camarero, H. Zhu, L. Zhu, A. M. Ellison, P. Ciais, and J. Peñuelas. 2016b. Species interactions slow warming-induced upward shifts of treelines on the Tibetan Plateau. Proceedings of the National Academy of Sciences USA 113:4380-4385.

Liu, H., W. A. Park, C. D. Allen, D. Guo, X. Wu, O. A. Anenkhonov, E. Liang, D. V. Sandanov, Y. Yin, and Z. Qi. 2013. Rapid warming accelerates tree growth decline in semi-arid forests of Inner Asia. Global Change Biology 19:2500-2510.

Liu, X., G. Xu, J. Grießinger, W. An, W. Wang, X. Zeng, G. Wu, and D. Qin. 2014. A shift in cloud cover over the southeastern Tibetan Plateau since 1600: evidence from regional tree-ring $\delta^{18} \mathrm{O}$ and its linkages to tropical oceans. Quaternary Science Reviews 88:55-68.

Lloyd, A. H. 1997. Response of tree-line populations of foxtail pine (Pinus balfouriana) to climate variation over the last 1000 years. Canadian Journal of Forest Research 27:936-942.

Lloyd, A. H., and L. J. Graumlich. 1997. Holocene dynamics of treeline forests in the Sierra Nevada. Ecology 78:1199-1210.

Maestre, F. T., et al. 2009. Shrub encroachment can reverse desertification in semi-arid Mediterranean grasslands. Ecology Letters 12:930-941.

Meyer, S. E., and B. K. Pendleton. 2005. Factors affecting seed germination and seedling establishment of a long-lived desert shrub (Coleogyne ramosissima: Rosaceae). Plant Ecology 178:171-187.

Milbau, A., B. J. Graae, A. Shevtsova, and I. Nijs. 2009. Effects of a warmer climate on seed germination in the subarctic. Annals of Botany 104:287-296.

Moreno, J. M., E. Zuazua, B. Pérez, B. Luna, A. Velasco, and V. R. de Dios. 2011. Rainfall patterns after fire differentially 
affect the recruitment of three Mediterranean shrubs. Biogeosciences 8:3721-3732.

Moyes, A. B., M. J. Germino, and L. M. Kueppers. 2015. Moisture rivals temperature in limiting photosynthesis by trees establishing beyond their cold-edge range limit under ambient and warmed conditions. New Phytologist 207:1005-1014.

Myers-Smith, I. H., and D. S. Hik. 2018. Climate warming as a driver of tundra shrubline advance. Journal of Ecology 106:547-560.

Myers-Smith, I. H., et al. 2011. Shrub expansion in tundra ecosystems: dynamics, impacts and research priorities. Environmental Research Letters 6:045509.

Naito, A. T., and D. M. Cairns. 2015. Patterns of shrub expansion in Alaskan arctic river corridors suggest phase transition. Ecology and Evolution 5:87-101.

Olsen, S. L., and K. Klanderud. 2014. Biotic interactions limit species richness in an alpine plant community, especially under experimental warming. Oikos 123:71-78.

Peñuelas, J., R. Ogaya, M. Boada, and A. S. Jump. 2007. Migration, invasion and decline: changes in recruitment and forest structure in a warming-linked shift of European beech forest in Catalonia (NE Spain). Ecography 30:829-837.

Piao, S., et al. 2014. Evidence for a weakening relationship between interannual temperature variability and northern vegetation activity. Nature Communications 5:5018.

Ren, P., S. Rossi, J. J. Camarero, A. M. Ellison, E. Liang, and J. Peñuelas. 2018. Critical temperature and precipitation thresholds for the onset of xylogenesis of Juniperus przewalskii in a semi-arid area of the northeastern Tibetan Plateau. Annals of Botany 121:617-624.

Sangüesa-Barreda, G., J. J. Camarero, J. Esper, J. D. Galván, and U. Büntgen. 2018. A millennium-long perspective on high-elevation pine recruitment in the Spanish central Pyrenees. Canadian Journal of Forest Research 48:1108-1113.

Shen, M., S. Piao, N. Cong, G. Zhang, and I. A. Jassens. 2015. Precipitation impacts on vegetation spring phenology on the Tibetan Plateau. Global Change Biology 21:3647-3656.

Sigdel, S. R., Y. Wang, J. J. Camarero, H. Zhu, E. Liang, and J. Peñuelas. 2018. Moisture-mediated responsiveness of treeline shifts to global warming in the Himalayas. Global Change Biology 24:5549-5559.

Stocker, T. F., D. Qin, G. K. Plattner, M. Tignor, S. K. Allen, J. Boschung, A. Nauels, Y. Xia, V. Bex, and P. M. Midgley, editors. 2013. The physical science basis. Contribution of Working Group I to the Fifth Assessment Report of the Intergovernmental Panel on Climate Change. Cambridge University Press, Cambridge, UK.
Sturm, M., J. P. McFadden, G. E. Liston, F. S. Chapin, C. H. Racine, and J. Holmgren. 2001. Snow-shrub interactions in Arctic tundra: A hypothesis with climatic implications. Journal of Climate 14:336-344.

Thompson, L. G., T. Yao, E. Mosley-Thompson, M. E. Davis, K. A. Henderson, and P. Lin. 2000. A high-resolution millennial record of the South Asian Monsoon from Himalayan ice cores. Science 289:1916-1919.

Thompson, L. G., E. Mosley-Thompson, H. Brecher, M. Davis, B. León, D. Les, P. Lin, T. Mashiotta, and K. Mountain. 2006. Abrupt tropical climate change: Past and present. Proceedings of the National Academy of Sciences USA 103:10536-10543.

Tian, L., V. Masson-Delmotte, M. Stievenard, T. Yao, and J. Jouzel. 2001. Tibetan Plateau summer monsoon northward extent revealed by measurements of water stable isotopes. Journal of Geophysical Research-Atmospheres 106:28081-28088.

Villalba, R., and T. T. Veblen. 1997. Regional patterns of tree population age structures in northern Patagonia: Climatic and disturbance influences. Journal of Ecology 85:113-124.

Waal, C., et al. 2009. Water and nutrients alter herbaceous competitive effects on tree seedlings in a semi-arid savanna. Journal of Ecology 97:430-439.

Walker, M. D., et al. 2006. Plant community responses to experimental warming across the tundra biome. Proceedings of the National Academy of Sciences USA 103:1342-1346.

Wang, Y., E. Liang, A. M. Ellison, X. Lu, and J. J. Camarero. 2015. Facilitation stabilizes moisture-controlled alpine juniper shrublines in the central Tibetan Plateau. Global and Planetary Change 132:20-30.

Wang, Y., N. Pederson, A. M. Ellison, H. L. Buckley, B. S. Case, E. Liang, and J. J. Camarero. 2016a. Increased stem density and competition may diminish the positive effects of warming at alpine treeline. Ecology 97:1668-1679.

Wang, Y., H. Zhu, E. Liang, and J. J. Camarero. 2016b. Impact of plot shape and size on the evaluation of treeline dynamics in the Tibetan Plateau. Trees 30:1045-1056.

Xu, C., H. Liu, O. A. Anenkhonov, A. Y. Korolyuk, D. V. Sandanov, L. D. Balsanova, B. B. Naidanov, and X. Wu. 2017. Long-term forest resilience to climate change indicated by mortality, regeneration, and growth in semiarid southern Siberia. Global Change Biology 23:2370-2382

Zhu, H., X. Shao, Z. Yin, P. Xu, Y. Xu, and H. Tian. 2011. August temperature variability in the southeastern Tibetan Plateau since AD 1385 inferred from tree rings. Palaeogeography, Palaeoclimatology, Palaeoecology 305:84-92.

\section{SUPPORTING INFORMATION}

Additional supporting information may be found in the online version of this article at http://onlinelibrary.wiley.com/doi/10. 1002/ecy.2557/suppinfo 